\title{
Effects of Organizational Climate on Employee Service Quality in Foreign Tobacco Company of Bangladesh
}

\author{
Dr. Rafique Ahmed Khan \\ Management Sciences Department \\ Bahria University Karachi Campus \\ Karachi, Pakistan \\ Professor Mohammad Khasro Miah, Ph.D. \\ School of Business, North South University \\ Dhaka 1229, Bangladesh
}

\begin{abstract}
Purpose: This paper aims to show the effects of organizational climate, including perceived organizational support and supervisory support on employees' service quality in the context of Foreign Tobacco Company of Bangladesh.

Methodology/Sampling: A total of 175 questionnaires were distributed among the respondents using non-probability, convenience sampling technique. Out of these, only 120 questionnaires were found suitable for data treatment. The data was treated with the help of software SPSS 20, applying correlation and linear regression analysis tools for testing the hypotheses.

Findings: The study established that there was a positive relationship of employee service quality with independent variables i.e. perceived organizational support, supervisory support and organizational climate. It also explained the extent to which the employees perceived their service quality in context of organizational climate and also the support they got from the firm. The study also identified some important areas that need further improvement in the service quality of employees.

Practical Implications: Findings of the study clearly indicate that in order to get better service from the employees, Foreign Tobacco Company needs to be more considerate by focusing on employees' problems, needs and accordingly provide them adequate support to mitigate their problems. The results also indicate that service quality of the employees is highly influenced by the organizational climate, supervisory support and organizational support. The managers at various tiers may seek help from the findings and render maximum possible support to the employees to enhance their commitment and loyalty.
\end{abstract}

Keywords: Service Quality, Supervisory Support, Organizational Climate, Organizational Performance.

\section{JEL Classification: L150, Q540}

\footnotetext{
* The material presented by the authors does not necessarily portray the viewpoint of the editors and the management of the Institute of Business \& Technology (IBT).

* Dr. Rafique Ahmed Khan: rak@bimcs.edu.pk

* Professor Mohammad Khasro Miah, Ph.D.: khasro@northsouth.edu

CJMSS is published by the Institute of Business and Technology (IBT). Main Ibrahim Hydri Road, Korangi Creek, Karachi-75190, Pakistan.
} 


\section{INTRODUCTION}

The Foreign Tobacco Company is one of the world's best manufacturers of the fine quality cigarettes whose different brands are sold in more than 200 markets across the globe. Right from its inception, it has been performing extremely well, in spite of a number of challenges. It is producing best-taste tobacco products of fine quality to the complete satisfaction of its customers. This tobacco business can be described in few words, as "From Seed to Smoke". The tobacco industry is committed to provide its consumers with pleasure through excellent products and by demonstrating that they are meeting its goals in ways that are consistent with reasonable societal expectations of a tobacco group operating in the $21^{\text {st }}$ century.

Foreign Tobacco Company (now a Public Limited Company) is managing its 85 factories in more than 66 countries and is manufacturing around 800 billion cigarettes per annum. For the past over hundred years, the company is of high stature which is maintaining it global position in the tobacco industry and enjoying international reputation for its fine quality tobacco. It has unique leading edge production techniques; it focuses on quality production and excellent distribution practices which enable it to deliver consistent quality premium products to its customers across the world

Foreign Tobacco Company was founded in 1910 with its original name "Imperial Tobacco Ltd." with its regional head office in Calcutta. Later, in 1926, a branch office was also created in the Sales Depot of Moulvi Bazar. Soon after independence of Bangladesh the company was formed in 1972 under the Companies Act 1913 but in 1973, it was converted into a Public Limited Company (PLC). Its name was changed from existing 'Bangladesh Tobacco to 'Foreign Tobacco Company' on March 22, 1998. Earlier, it was incorporated under the Act 1913 on $2^{\text {nd }}$ February 1972, as a subsidiary of Imperial Tobacco Ltd.

Main business of the tobacco company involves growing and processing of leaf tobacco and manufacturing, marketing and distribution of cigarettes and pipe tobacco throughout Bangladesh. By now the customer markets have expanded across the globe, including countries like Russia, Germany, Poland, U.K., New Zealand etc. The main theme of the company is "Quality First" which has gained lot of popularity during the past few decades and by virtue of offering unique quality product to its clientele, it has earned big repute in the local as well as foreign markets.

\subsection{Purpose of the Research}

The main reason behind this research was to determine the extent to which some independent variables including perceived organizational support, supervisory support, and overall organizational climate were related with employee service quality (Dependent Variable). Employee service quality is essentially considered to be an important variable for ensuring better quality production and services provided by these employees. It is also true that if the service quality of the employees is not appropriate, the long term success of organization becomes questionable. Therefore, it is necessary to identify the factors responsible for ensuring better quality services. This study was indeed undertaken to determine whether or not, employee service quality is influenced by perceived organizational support, supervisory 
support, and organizational climate. The research was specific in nature since there was no such study conducted in the past known history.

\subsection{Problem Statement}

In today's cut-throat competition, maintaining an employee-conducive culture is quite a challenging task. To ensure a sustained leading-edge position in the relevant industry, the world renowned organizations provide full support to their employees to keep them satisfied and committed. An organization's support and care is also acknowledged by the employees in term of value addition and continuous improvement. According to Eisenberger et al. (1986), the concept of organization's support has been found highly effective for interpretation of organizational commitment in a social exchange framework. When employees hope to receive better compensation and rewards, their perceived organizational support also increases. As a result, their commitment and efforts towards achieving organizational goals increases, especially by providing superior service to customers.

Once employees understand that their performance is being monitored and a variety of socioeconomic assistance is provided by the superiors, it boosts their motivation towards work (Babin \& Boles, 2002; Kopelman et al., 2000), and they exert more effort at the workplace. According to Schneider et al. (2002), workplace climate is what employees perceive about practices, procedures and specific productive behavior that is compensated in a particular atmosphere. Hence, in the current study, the service climate was used as an added variable to investigate the relationship between organizational climate and employee service quality in the context of Foreign Tobacco of Bangladesh. Through this study, an effort was made to determine the association between independent Variables (i.e. perceived organizational support, supervisory support, organizational climate) and dependent variable (i.e. employee service quality) in Foreign Tobacco Company of Bangladesh.

\section{LITERATURE REVIEW AND HYPOTHESES BUILDING}

A number of researchers have expressed their views and applied different models to test the impact of organizational support, supervisory support and organizational climate on employee service quality. Lot of literature was studied which was available on the subject; however, the salient part of the relevant literature was chosen in support of the research.

\subsection{Perceived organizational support and employee service quality}

Perceived organizational support (POS) is considered to be a effective motivator for the employees and is defined as the "global belief concerning the extent to which the organization values its employees' contribution \& also takes care of their well being". He further argued that if employees possess perception of support by the organization, their loyalty, commitment and service quality automatically gets enhanced (Eisenberger et al. 1986). According to Chun H. et al. (2004), organizational support is positively related to job satisfaction which further leads to enhancement of employee service quality. A comprehensive study, undertaken by LaRocco et al. (2004) on 'the impact of social support at workplace' has pointed out that whenever employees have a feeling of continuous support by the organization, they display high level of job satisfaction and resultantly deliver better performance. When employees 
perceive greater support by the organization, their quest to reciprocate with better value addition and display citizenship behavior energizes; it ultimately helps them display positive attitude towards the organization (Bettencourt \& Brown, 2005). According to Frone et al. (2007), provision of support by the colleagues and supervisors has a positive influence on employee job satisfaction. He has also proved that supervisory support is positively related to temporal work commitment. Bennet et al. (2001) have observed that the supervisory support and organizational acknowledgement are positively related to job satisfaction. Moreover, a number of studies by Eisenberger et al., (1990); Guzzo et al., (1994); Wayne et al., (1997). As mentioned by Schaubroeck and Fink (2004), there is a positive relationship between support and organizational commitment. However, even though most literature on organizational support is focused on relationships involving satisfaction and commitment, lot of research has supported that the relationships between organizational support and employee performance is positive (Armeli et al., 1998; Eisenberger et al., 1986, 1990).

An important method to support teamwork is to enhance group cohesiveness and efficiency with the help of training. In order to be successful as team member, employees should be suitably trained in relevant fields, including provision of technical and professional knowledge, interpersonal and team working skills, etc. As a result of skill enhancement through effective training, overall team performance can be improved by developing employees' skills needed to become useful members of the team (Chun H., et Al., 2004). Similarly, through positive reinforcement in the form of appreciation and rewards can help improve employees' motivation and commitment. As concluded by Hyatt and Ruddy (2007), teams which receive requisite support of superiors and organization as a whole tended to be more effective at their respective workplace.

\section{Hypothesis 1: There is a significant relationship between perceived organizational support and employee service quality in Foreign Tobacco Company of Bangladesh.}

\subsection{Supervisory Support and Employee Service Quality}

In their book on "Personnel Psychology", C. A. Shriesheim, \& R.M Stodgigill have indicated that supervisory support acts as a tool to enhanced employee motivation and is also related with leaders' behavior who are concerned with promoting comfort and wellbeing of their subordinates. It is assumed that employees who perceive that the superiors are their leaders and provide them full support, they display more dedication towards their organization goals than the ones who do not possess such a perception about their managers (Johnston, M.W., Parasuraman, A., Futrell, C.M. and Black, B.C, 2000). According to Fry (2001) and Johnston (2000), consideration towards employees leads to reduction in role conflicts and their service quality automatically increases. In the absence of complete knowledge about organization demands from them, they will not be able to do justice with their job. Hence, the role of supervisors is becoming more demanding as they are required to act as a bridge between the top management $\&$ the subordinates. In the context of social contract, role of employees influences fair distribution of rewards by the supervisor. Hence, distributive justice about the rewards shall increase the trust between employees and supervisors. According to Babin \& Boles, 2002, "the degree of supervisory support does have an impact on the subordinate's motivation, job satisfaction, and performance improvement". As mentioned by Frone et al. (2007), job satisfaction of employee increases when they get a appropriate support from colleagues as well as from the supervisor. Bennet et al. (2001) also mentioned about the 
positive relationship between supervisory support and organizational acknowledgement which leads to job satisfaction. As concluded by Eisenberger et al. (2001), managerial support is correlated with effective employee commitment towards achieving organization's long term objectives in service delivery is strongly influenced by the action taken by the manager. When employees perceive that their immediate supervisors are always concerned about their well being \& render all possible support, they tend to reciprocate by demonstrating more commitment behavior towards the job (Babin \& Boles, 2002; Kopelman et al., 2000). In the absence whole hearted support by the employees, even brilliant decisions fail to bring desired results. A true leadership can be demonstrated through effective implementation of decisions and committed employees act as a means to end (Robie et al., 2001). In most of the cases, supervisors need to play such a leadership role quite effectively. As a figurehead, the supervisor performs legal, moral, and financial duties in the organization (Jonathan, R.A., 2006). In order to strengthen the service quality skills of employees and extract optimum dedication, a supervisor display lot of concern for their well being. Trust on supervisor helps the employees to enhance the service effort. The employee's commitment towards the organizations goal is highly influenced by the manager's supportive role. The service quality of the employee will be strongly influenced by the leadership quality of the supervisor (Zeithaml, V.A., Parasuraman, A. \& Berry, L.L., 2000). Supervisor's behavior towards his/her employees also influences the service quality of the employees. According to Cohen et al. (2003), a supervisor needs to focus on leadership behavior, which may include, encouraging self-observation / selfevaluation, encouraging self-goal setting, encouraging self-reinforcement, encouraging selfcriticism, encouraging self-expectation and encouraging rehearsal. A leader encourages the group members to monitor and continuously assess their performance levels. Self-goal setting also helps in achieving performance goals, effectively. This behavior also helps employees in setting realistic but challenging goals. Self-reinforcement facilitates the recognition and behavior. Self-management, in turn, enables team members to exhibit performance-enhancing behaviors that lead to increased group effectiveness. As group identity grows, it should promote a healthy work cycle in which the supervisor takes on the role of facilitator.

\section{Hypothesis 2: There is a significant relationship between supervisory support and employee service quality in Foreign Tobacco Company of Bangladesh.}

\subsection{Organizational Climate and Employee Service Quality}

In his field theory of motivation, Lewin (1951) has amply discussed the concept of organizational climate (OC); he contended that better climate attributes to enhancement of the employee motivation. There are a number of perceptions about organizational climate which are found to be very effective identifier of employee behavior in organizations; it is considered that there relationship between characteristics of good work environment and individuals' responses is always positive (Campbell, Dunnette, Lawler, \& Weick, 2003). Organizational climate refers to how employees perceive and interpret the organizational environments and it consists of more empirically accessible elements such as behavioral and attitudinal characteristics (Al-Aamri, 2009/2010). As mentioned by Moran and Volkwein (2002), organizational climate is a relatively enduring characteristic of an organization which distinguishes it from other organizations. It includes members' collective perceptions about their organization with respect to such dimensions as autonomy, trust, cohesiveness, support, recognition, innovation and fairness. 
The perception of employees regarding work environment is usually called psychological climate. Organizational climate includes processes, practices and behaviors which are rewarded and supported by the management in an organization. In today's business environment, organizational climate is gaining more importance than what it used to be few decades ago, due to less stability and less predictability in the external and internal environments. As pointed out by Kim and Mauborgne (2003), fundamental challenge faced today by the organizations is that they need to create a climate that may facilitate employees voluntarily develop their creativity and expertise. Moreover, employees' empowerment also has a significant impact on organizational climate, in terms of participative decision making to carry on with the organization or quitting the job. Al-Aamri (2009/2010) argued that most of the employees' work related decisions, such as participating, producing and quitting, are influenced by the organizational climate of which they are the part. According to James and James (2004), perception of the organizational atmosphere creates personal significance for employees through assessment, in which a cognitive illustration of the features of work environment are interpreted in terms of the individual's standards. Environmental attributes, appearing from situational referents, consist of safety, innovation, customer service (Schneider et al., 2002), support, cost-cutting and others. According to an earlier study by Pritchard and Karasick, organizational climate contains 11 dimensions, including autonomy, conflict versus cooperation, social relations, structure and level of rewards, performance- reward dependency, motivation to achieve, status polarization, flexibility, and innovation, decision centralization and supportiveness. They discovered that all the dimensions except autonomy were related to job satisfaction. So we can come up with the thought that if the organizational climate influences the employee positively, she/he will be satisfied with the job and once job satisfaction is ensured she / he might deliver better service.

An important organizational climate variable out of a variety of others factors is the supportive management which defines how managers and supervisors support, trust and create a conducive working environment for the employees. It is clear that an organizational climate consists of cumulative impressions, expectations and feelings of the members of local work units, which in turn affect members' relationship with supervisors and with one another within own unit and also with other units. According, to Brown \& Peterson (2002), work effort is considered to be the mediator between motivation and job performance. As quoted by Gardner et al, 2001, there is a significant difference between work effort and employee performance. Committed employees are believed to be highly dedicated towards their job, invest more time, energy and use their talent to the best interest of organization. The employee's commitment to the organization and its long-term goal of excellence in service delivery is however strongly influenced by managerial action. Hence, organizations need managers who are capable to reinforce a service vision, who create a culture of teamwork and remove obstacles from the path of employees who want to satisfy the service quality needs of their customers. The quality of leadership provided by middle management will significantly influence the level of service quality provided by employees at the lower organizational levels (Zeithaml, V.A., Parasuraman, A. \& Berry, L.L, 2000).

\section{Hypothesis 3: There is a significant relationship between organizational climate and employee service quality in Foreign Tobacco Company of Bangladesh.}




\section{RESEARCH METHODOLOGY}

The present research was aimed at determining correlation among different variables; through correlation, relationship among perceived organizational support, supervisory support and organizational climate \& employee service quality within the context of Foreign Tobacco in Bangladesh, was determined. Here in this research, the independent variables were perceived organizational support, supervisory support, and organizational climate whereas employee service quality was the dependent variable.

\subsection{Type of Research}

This research is exploratory in nature which is based on quantitative data collected through a questionnaire from 120 employees of the company.

\subsection{Research approach}

In order to get the answer of research questions, data was collected from the employees during the time October 2014 to December 2014, of the Tobacco Company in Bangladesh. The context of the research was explained to the participants.

\subsection{Sample Size and Sampling Technique}

All employees of the Foreign Tobacco Company are the population of this study. The respondents were chosen in a random manner \& each of the respondents participated voluntarily. Quantitative data were gathered by distributing questionnaires among 175 employees who are working in the Regional Trade Marketing Office in Chittagong of Foreign Tobacco Company and finally 120 questionnaires were accepted.

\subsection{Survey Instrument}

Like most of the other researches, the questionnaire had been adopted from previous empirical studies. The Psychometric Properties of the Scale items were evaluated using Cronbach's Coefficient Alpha, which is reported to be the preferred method (William \& Anuchit, 2002). In general, the acceptable range of alpha value is greater than 0.50 .

\subsection{Data Collection}

A Structured questionnaire was used in this study to collect data from the managerial employees. The researchers utilized four different sets of questionnaires to measure the variables Perceived organizational support was measured by adopting questions (question 1 to 5) developed by Eisenberger et al. (1986). Supervisory support was measured by using four items (question 6 to 9). This scale was adopted from Eisenberger, Stinglahamber, Vandenberghe, Sucharski \& Rhoades (2002). Organizational climate was measured by using four items (question 10 to 13) and the scale was adopted from Al-Amari (2009/2010). 
Similarly, employees' service quality was measured by five items (question 14 to 18 ) and the scale used was adopted from John J.D. (2003).

\section{ANALYSIS OF DATA}

Research hypotheses were tested with the help of Statistical tools, Pearson's correlation and regression analysis; Pearson's Correlation analysis was used to find out the relationship between the independent and dependent variables. Correlation analysis is the statistical tool that can be used to describe the degree to which one variable is linearly related to another (William, and Anuchit, 2002); the results obtained have been discussed in the ensuing paragraphs.

\subsection{Factor Analysis}

Exploratory principle, component factor analysis (CFA) identified four variables namely, Perceived organizational support (POS), Supervisory support (SS), Organizational climate (OC) and Employee service quality (ESQ), as indicated in Table 1.

Table 1: Factor Analysis Result

\begin{tabular}{|c|c|c|c|c|}
\hline Variables & $\mathrm{M}$ & SD & F & Alpha \\
\hline \multicolumn{5}{|l|}{ Perceived organizational support } \\
\hline 1. My organization values my contribution to its well-being & 3.6364 & .92932 & .760 & \multirow[t]{5}{*}{.830} \\
\hline 2. My organization strongly considers my goals and values & 3.6061 & .78817 & .596 & \\
\hline 3. My organization cares about my opinions & 3.6364 & 1.05529 & .886 & \\
\hline 4. My organization takes pride in my accomplishments at work & 4.0000 & .70711 & .835 & \\
\hline $\begin{array}{l}\text { 5. My organization tries to make my job as interesting as } \\
\text { Possible }\end{array}$ & 3.7879 & .89294 & .783 & \\
\hline \multicolumn{5}{|l|}{ Supervisor support } \\
\hline 6. My supervisor is friendly and approachable & 3.9091 & .87905 & .860 & \multirow[t]{4}{*}{.836} \\
\hline 7. My supervisor helps make my job more pleasant & 3.8485 & 1.12142 & .891 & \\
\hline 8. My supervisor treats all workers as his equals & 3.6061 & .89928 & .644 & \\
\hline 9. My supervisor looks out for the personal welfare of group members & 3.7273 & .91079 & .876 & \\
\hline \multicolumn{5}{|l|}{ Organizational Climate } \\
\hline 10. My boss is flexible about how I accomplish my job objectives & 3.5455 & .97118 & .889 & \multirow[t]{4}{*}{.820} \\
\hline 11. My boss is supportive of my ideas $\&$ ways of getting things done & 3.7576 & .83030 & .873 & \\
\hline 12. My boss gives me the authority to do my job as I see fit & 3.6061 & .99810 & .867 & \\
\hline 13. I can trust my boss to back me up on decisions I take in the field & 3.7576 & .75126 & .562 & \\
\hline \multicolumn{5}{|l|}{ Employee Service Quality } \\
\hline 14. Providing prompt service & 3.7879 & .85723 & .795 & \multirow[t]{5}{*}{.824} \\
\hline 15. Never being too busy to respond to my request & 3.8182 & .91701 & .660 & \\
\hline 16. Instilling confidence in me & 3.8182 & 1.0445 & .842 & \\
\hline 17. Adequate knowledge to answer my questions & 3.9697 & .76994 & .705 & \\
\hline 18. Courteousness of employee & 3.9697 & .84723 & .832 & \\
\hline
\end{tabular}


Result of factor analysis, displayed in Table 1, is explained hereunder:

The first factor was 'perceived organizational support', which had five items including value of contribution, considering goals and values, considering opinion, taking pride in work accomplishment \& making job interesting. This factor accounted for $60 \%$ of explained variance and was considered as most vital for this study.

The second factor 'supervisory support' had four items which comprised of supervisor being friendly, making job more pleasant, treating workers equally \& welfare of group members. This factor explained $68 \%$ of variance.

The third factor 'organizational climate' accounted for $66 \%$ of variance. This factor was defined by four items that were primarily related to understanding the organizational climate by knowing job objectives, support for ideas and work accomplishment, authority \& backing up by the supervisors for any decision taken. This factor was used to understand the organizational climate of the organization.

The fourth factor 'employee service quality' accounted for 59\% of variance and comprised of five items, related to providing information regarding the service quality by assessing promptness of service, responding to request, instilling confidence, and giving knowledge to answer my question \& courteousness of employees.

\subsection{Correlation coefficients and Explanation}

Table 2: Correlation coefficients among all variables

\begin{tabular}{|c|c|c|c|c|c|c|c|c|c|}
\hline Variables & 1 & 2 & 3 & 4 & 5 & 6 & 7 & 8 & 9 \\
\hline $\begin{array}{ll}\text { 1. Employee } \\
\text { Service }\end{array}$ & 1 & & & & & & & & \\
\hline Quality (ESQ) & & & & & & & & & \\
\hline $\begin{array}{l}\text { 2. Perceived } \\
\text { Organization } \\
\text { Support (POS) }\end{array}$ & $.757^{* *}$ & 1 & & & & & & & \\
\hline $\begin{array}{l}\text { 3. Supervisory } \\
\text { Support (SS) }\end{array}$ & $.828^{* *}$ & $.787^{* *}$ & 1 & & & & & & \\
\hline $\begin{array}{l}\text { 4. Organizational } \\
\text { Climate (OC) }\end{array}$ & $.861^{* *}$ & $.877^{* *}$ & $.810^{* *}$ & 1 & & & & & \\
\hline 5. Position & $.536^{* *}$ & $.415^{*}$ & .290 & $.481^{* *}$ & 1 & & & & \\
\hline 6. Gender & $-.422^{*}$ & $-.386^{*}$ & $-.450^{* *}$ & $-.427^{*}$ & -.141 & 1 & & & \\
\hline 7. Age & $.364^{*}$ & .241 & .155 & .299 & $.859^{* *}$ & .041 & 1 & & \\
\hline 8. Educational Level & .301 & .164 & .109 & .240 & $.579^{* *}$ & -.095 & $.680^{* *}$ & 1 & \\
\hline 9. Tenure of Job & .325 & .089 & .042 & .151 & $.638^{* *}$ & .060 & $.772^{* *}$ & $.793^{* *}$ & 1 \\
\hline
\end{tabular}

** Correlation is significant at the 0.01 level (2-tailed).

* Correlation is significant at the 0.05 level (2-tailed). 


\section{Explanation:}

Table 2 shows the correlation among different variables of the study. The result has indicated that POS, SS and OC have significant influence over employee service quality (ESQ) in context of Foreign Tobacco Company. Study indicates that higher levels of employee service quality is positively associated with POS $(\mathrm{r}=.76, \mathrm{p}<.01)$; $\mathrm{SS}(\mathrm{r}=.83, \mathrm{p}<.01)$; OC $(\mathrm{r}=.86, \mathrm{p}<.01)$. On the basis of the results, all hypotheses of the present study have been accepted.

\subsection{Regression Analysis Results and Explanation}

Table 3: Regression analysis among all variables used for this study

\begin{tabular}{|l|l|l|l|}
\hline Variables & \multicolumn{3}{|l|}{ Sig } \\
\cline { 2 - 4 } & $\mathbf{B}$ & $\mathbf{t}$ & .000 \\
\hline Perceived organizational support & .118 & .727 & .003 \\
\hline Perceived supervisory support & .402 & 3.357 & .001 \\
\hline Perceived organizational climate & .477 & 2.771 & .152 \\
\hline Position & .156 & 1.479 & .700 \\
\hline Gender & -.065 & -.390 & .204 \\
\hline Age & -.217 & -1.305 & .330 \\
\hline Educational Level & -.187 & -.993 & .008 \\
\hline Tenure of Job & .530 & 2.534 & .932 \\
\hline$R$ & & & .868 \\
\hline$R^{2}$ & & & .824 \\
\hline Adjusted $R^{2}$ & & & \\
\hline
\end{tabular}

\section{Explanation}

As displayed in Table 3, perceived organizational support values obtained i.e. $\beta=.12$, $p$ value $.000(\mathrm{p}<.05)$, indicate a positive and significant effect on employee service quality. In case of supervisory support the value of $\beta .=.40, \mathrm{p}<.05$ (i.e. .003 ), which clearly indicates that supervisory support has significant effect over employee service quality at the Foreign Tobacco Company. The employees of the organization verified that supervisors' support has positive and strong effect on the service quality of the employees. Perceived organizational climate has also shown significant support with employee service quality. The result i.e. value of $\beta=.48$, and value of $\mathrm{P}$ is .001 (which is less than .05); it indicates that organizational climate is positively related with employee service quality. These findings clearly indicate that perceived supervisory support and organizational climate are positively associated with employee service quality.

Job role or position in the organization is positively associated with employee service quality. The position of employees creates better commitment and makes them more responsible for better performance which ultimately increases the service quality. Age, Gender and Educational qualification have shown a negative association but their impact on employee service quality is not significant. Finally the statistics in respect of 'tenure of job' shows ( $\beta=$ $.53, \mathrm{p}<.05)$ that it has a significant positive associated with employee service quality. 
In addition, the adjusted $\mathrm{R}^{2}$ was found significant as $\mathrm{R}^{2}=.868$ and adjusted $\mathrm{R}^{2}=.824$ for the organization. Hence, results indicate that the hypothesis 2 and 3 are strongly supported by the regression analysis.

\subsection{Critical Debate}

From the findings, it is clear that all independent variables, i.e. POS, SS \& OC, are significantly correlated with Employee Service Quality. The study supports our hypothesis and made it clear that these variables do have a positive and strong relationship with the service quality of the employees. Employee service quality is very important for any organization as the employees are the ones who bring success to the organization and can also increase performance of the organization (Eisenberger, et al., 1986). A number of researchers (Eisenberger, Stinglahamber, Vandenberghe, Sucharski, Rhoades, 2002, Al-Amari, 2009/2010, John J.D., 2003) have found that perceived organizational support, supervisory support and organizational climate are three very important factors that help the employees in performing better.

The study showed that perceived organizational support is a key factor to improve employee service quality. With the implementation of work teams, employees need specific training in different areas (technical and professional updating, interpersonal and team working skills, etc.). The researcher (Chun H., et al., 2004) has found that employees getting more support show higher job satisfaction and that satisfaction leads to higher work effort which results higher quality of the service. Another form of support is the appreciation and rewards offered to employees. Hyatt and Ruddy (2007) found that the teams obtaining the necessary support of superiors and organization tended to be more effective.

The study supporting supervisory support has positive and strong correlation with employees' service quality. An organization which truly pursues service excellence needs middle-level managers and supervisors who rise above mere managing and leading. It requires managers who establish and reinforce a service vision by creating a culture of teamwork and performance. Supervisors remove obstacles from the paths of employees who want to satisfy the service quality. The service quality of the employee will get strongly influenced by the leadership quality of the supervisor (Zeithaml, V.A., Parasuraman, A. \& Berry, L.L., 2000). Supervisors' behavior towards their employees also influences the service quality of the employees.

From the study it has been found that organizational climate is another very good influencer of the employee's service quality. Many researchers including Schneider et al. (2002), AlShammari (2004), Brown \& Peterson, (2002) have found significant relationship between organizational climate and the service quality of employees. Burruss (2001) suggested that it is no surprise that organizational climate is an excellent predictor of firm and employee performance. Employees will feel positive about their work if they get support from their work environment (Babin \& Boles, 2002; Kopelman et al., 2000) and will display more devotion at the workplace (Brown \& Peterson, 2002). 


\section{CONCLUSION AND IMPLICATIONS}

The study has proved the positive impact of perceived organizational support, supervisory support and organizational climate on employee service quality in context of Foreign Tobacco Company of Bangladesh. The research result might also be applicable in case of other organizations. The study has supported the importance of organizational climate, supervisory support and organizational support for firm's success as they have a significant impact on employee service. Firms should concentrate on creating a congenial working atmosphere where supervisors are friendly towards the employees and there is adequate support from the firm itself to enhance the employee service quality. In the long run, we can say that the above relationship provides significant insight to enhance the quality of the employees.

The relationship between different variables, found from the study, clearly indicates that to get better service from its employees, the Company should focus more on their problems, needs, welfare and accordingly provide adequate support to resolve their issues. The results also indicate that service quality of the employees is highly influenced by the organizational climate, supervisory support and organizational support. This support can only be implied if the HR department of an organization is responsible, more considerate and empathetic towards employees in terms of providing facilities or support as and when needed. Conversely, in the absence of adequate support to the employees by the organization, their service quality would not be forthcoming. Such a support would also induce a strong sense of belongingness in the employees, leading to achievement of desired organizational objectives.

The essential contributions of climate, culture and support over service quality help an organization to successfully achieve its goals and objectives. Thus, the management needs to be careful and conscious about this aspect. The study, however, has some limitations. The present study was limited to a small sample size of respondents, so it might not have reflected opinion of entire population. The respondents gave information about the support system provided by the organization, its supervisor, work climate and the quality of service, so there might be biasness in their response, which might had affected the research results in some cases. Another limitation was the time constraint, especially due to official commitments of the authors by virtue of having a full time job. Future research may include a huge sample size and also include other organizations to statistically authenticate the findings of the present study. For advanced investigation on the connection among the studied constructs, future research may also highlight on longitudinal study. It would be perfect to take up a bigger sample scale so that methodological limits could be avoided. Further research may also highlight the theoretical part as well as put more emphasis on qualitative data, as well. It can be concluded that an effective HR department can add more value and help organization in achieving sustained status in the tobacco industry, not only at domestic but also at International level.

\section{REFERENCES}

Al-Aamri, A.D. (2009/2010), Employee Motivating in Private Organization. University of Malaysia, Vol. 1, pp. 43-58.

Al-Shammari (2004), An analysis of the organisational climate and effectiveness in Jordanian industrial companies, Dirasat, Vol. 21 No. 2, pp. 43-48. 
Armeli, S., Eisenberger, R.T., Fasolo, P. \& Lynch, P. (1998), Perceived organizational support and police performance: the moderating influence of socio-emotional needs. Journal of Applied Psychology, Vol. 83 No. 2, pp. 88-297.

Babin, B.J. \& Boles, J.S. (2002). The effects of perceived co-worker involvement and supervisor support on service provider role stress, performance and job satisfaction. Journal of Retailing, Vol. 72 No. 1, pp. 57-75.

Bennet, P., Lowe, R., Mattwes, V., Dourali, M. \& Tattersall, A. (2001). Stress in nurses: coping, managerial support and work demand. Stress and Health: Journal of the International Society for the Investigation of Stress, Vol. 7 No. 1, pp. 55-63.

Bettencourt, L.A. \& Brown, S.W. (2005). Contact employees: relationships among workplace fairness, job satisfaction and prosocial service behavior. Journal of Retailing, Vol. 73 No. 1, pp. 39-61.

Brown, S.P. \& Peterson, R.A. (2002). The effect of effort on sales performance and job satisfaction. Journal of Marketing, Vol. 58 No. 2, pp. 70-80.

Burruss, J. (2001). Managing for motivation and performance improvement. In Boulter, N., Dalziel, M. and Hill, J. (Eds). People and Competencies: The Route to Competitive Advantage, London: Kogan Page.

Campbell, J.P., Dunnette, M.D., Lawler, E.E. \& Weick, K.E. (2003), Managerial Behaviour,

Chun, H., Cynthia, L., Denise M. R. (2004). Employment Relationships in China: Do Workers Relate to the Organization or to People? Organization Science, Vol. 15, No. 2 (Mar. Apr., 2004), pp. 232-240

Cohen, S.G., Ledford, G.E. Jr \& Spreitzer, G.M. (2003). A predictive model of self-managing work team effectiveness. Human Relations, Vol. 49 No. 5, pp. 643-76.

Cooper, D. R., \& Schindler, P.S. (2002). Business research Methods (6th ed.). Boston: Erwin McGraw - Hill.

Cronbach, L.J. (1951). Coefficient alpha and the internal structure of tests. Psychometrika, Vol. 16, pp. 297-334.

Eisenberger, R., Huntington, R., Hutchison, S. \& Sowa, D. (1986). Perceived organizational support. Journal of Applied Psychology, Vol. 71 No. 3, pp. 500-7. 
Eisenberger, R., Armeli, S. \& Rexwinkel, B. (2001). Reciprocation of perceived organizational support. Journal of Applied Psychology, Vol. 86 No. 1, pp. 42-51.

Frone, M., Yardley, J.K. \&Markel, K.S. (2007). Developing and testing an integrative model of the work-family interface. Journal of Vocational Behavior, Vol. 50 No. 2, pp. 145-67.

Fry, L.W., Futrell, C.M., Parasuraman, A. \& Chmielewski, M.A. ( 2001), An analysis of alternative causal models of salesperson role perceptions and work-related attitudes. Journal of Marketing Research, Vol. 23 No. 2, pp. 153-63.

Gardner, D.G., Dunham, R.B., Cummings, L.L. \& Pierce, J.L. (2001). Focus of attention at work: construct definition and empirical validation. Journal of Occupational Psychology, Vol. 62, pp. 61-77.

Hyatt, D.E. \& Ruddy, T.M. (2007). An examination of the relationship between work group characteristics and performance: once more into the breach. Personnel Psychology, Vol. 50 No. 3 , pp. 553-85.

James, L.R. \& James, L.A. (2004) . The meaning of organizations: he role of cognition and values. In Czepiel, J.A., Solomon, M.R. \& Surprenant, C.F. (Eds). The Service Encounter, Lexington Books, Lexington, MA, pp. 127-47.

John, J.D., (2003). The Effects of employee service quality provision and customer personality traits on customer particiapation, satisfaction, and repurchase intentions, Louisiana State University, Personal Psychology, Vol. 49, pp. 31-51.

Johnston, M.W., Parasuraman, A., Futrell, C.M. \& Black, B.C. (2000). A longitudinal assessment of the impact of selected organizational influences on salespeople's organizational commitment during early employment. Journal of Marketing Research, Vol. 27 No. 3, pp. 33344.

Jonathon, R.A. (2006). Managing employees in the service sector: A literature review and conceptual development, Journal of Business and Psychology, Vol. 20, No. 4 (Summer, 2006), pp. 501-523.

Kim, W. \& Mauborgne, R. (2003). Fair process: management in the knowledge economy. Harvard Business Review, Vol. 81 No. 1, pp. 127-36.

Kopelman, R.E., Brief, A.P. \& Guzzo, R.A. (2000). The role of climate and culture in productivity. In Schneider, B. (Ed.). Organizational Climate and Culture, Jossey-Bass, San Francisco, CA, pp. 282-313.

LaRocco, J.M., House, J.S. \& French, J.R. (2004). Social support, occupational stress, and health. Journal of Health and Social Behavior, Vol. 21 No. 3, pp. 202-18 
Lewin K. (1951) 'Field Theory in Social Science', Harper and Row, New York.

Moran, E.T. \& Volkwein, J.F. (2002). The cultural approach to the formation of organizational culture. Human Relations, Vol. 45 No. 1, pp. 19-47.

Nutt, P.C. (1993). The formulation processes and tactics used in organizational decision-making. Organization Science, Vol. 4 No. 2, pp. 246-75.

Ranaweera, C., \& Prabhu, J. (2003). The influence of satisfaction, trust and switching barriers on customer retention in a continuous purchasing setting. International Journal of Service Industry Management, 14(4), 374-395.

Roadhes, L. \& Eisenberger, R. (2002). Perceived organizational support: a review of the literature. Journal of Applied Psychology, Vol. 87, pp. 698-714.

Robie, C., Johnson, K.M., Nilsen, D. \& Hazucha, J.F. (2001). The right stuff: understanding cultural differences in leadership performance. Journal of Management Development, Vol. 20 No. 7, pp. 639-49.

Schaubroeck, J. \& Fink, L.S. (2004). Facilitating and inhibiting effects of job control and social support on stress outcomes and role behavior: a contingency model. Journal of Organizational Behavior, Vol. 19 No. 2, pp. 167-95.

Schneider, B., White, S.S. \& Paul M.C. (2002). Linking service climate and customer perceptions of service quality: test of a causal model. Journal of Applied Psychology, Vol. 83 No. 2, pp. $150-63$.

Sharma, N. and Patterson, P.G. (2000). "Switching costs, alternative attractiveness and experience as moderators of relationship commitment in professional consumer services", International Journal of Service Industry Management, 11(5), pp. 470-490.

Stinglhamber, F. \& Vanderbergue, C. (2003). Organizational and supervisors as sources of support and targets of commitment: a longitudinal study. Journal of Organizational Behavior, Vol. 24, pp. 251-70.

Wayne, S.J., Shore, L.M.\& Liden, R.C. (1997). Perceived organizational support and leadermember exchange: a social exchange perspective. Academy of Management Journal, Vol. 40 No. 1, pp. 82-111.

Zeithaml, V.A., Parasuraman, A. \& Berry, L.L. (2000). Delivering Service Quality: Balancing Perceptions and Expectations. NY: Free Press. 